\title{
Abnormal mitochondrial function in locomotor and respiratory muscles of COPD patients
}

\author{
L. Puente-Maestu*, J. Pérez-Parra*, R. Godoy*, N. Moreno\#, A. Tejedor", \\ F. González-Aragoneses ${ }^{\top}$, J-L. Bravo ${ }^{+}$, F. Villar Álvarez ${ }^{\S, f}$, \\ S. Camaño and A. Agustíf,**\#\#
}

ABSTRACT: Several cellular and molecular alterations have been described in skeletal and respiratory muscles of patients with chronic obstructive pulmonary disease (COPD), but information on potential abnormalities of mitochondrial function is scarce. The aim of the present study was to investigate mitochondrial function in the vastus lateralis (VL) and external intercostalis (EI) of COPD patients.

Biopsies from VL and El were obtained during surgery for lung cancer in 13 patients with mild to moderate COPD (age $68 \pm 6 \mathrm{yrs}$, forced expiratory volume in one second (FEV 1 ) $66 \pm 15 \%$ predicted) and 19 control subjects (age $67 \pm 9 \mathrm{yrs}$, FEV $195 \pm 18 \%$ pred). State 3 and 4 mitochondrial oxygen consumption $\left(V^{\prime} \mathrm{O}_{2}, \mathrm{~m}\right)$, ATP synthesis, citrate synthase, cytochrome oxidase (COX) and complex I-III activities, as well as reactive oxygen species (ROS) production, were determined.

In COPD patients, in both muscles, COX activity (VL: COPD $3.0 \pm 0.8$ versus control $2.0 \pm 0.8$; El: $3.7 \pm 1.6$ versus $2.4 \pm 0.9 \mu \mathrm{mol} \cdot \mathrm{min}^{-1} \cdot \mathrm{mg}^{-1}$ ) and ROS production (VL: $1,643 \pm 290$ versus $1,285 \pm 468$; El: $1,033 \pm 210$ versus $848 \pm 288$ arbitrary units) were increased, whereas state $3 V^{\prime} O_{2}, m$ was reduced (VL: $2.9 \pm 0.3$ versus $3.6 \pm 0.4$; El: $3.6 \pm 0.3$ versus $4.1 \pm 0.4 \mathrm{mmol} \cdot \mathrm{min}^{-1} \cdot \mathrm{kg}^{-1}$ ).

Skeletal muscle mitochondria of patients with chronic obstructive pulmonary disease show electron transport chain blockade and excessive production of reactive oxygen species. The concurrent involvement of both vastus lateralis and external intercostalis suggests a systemic (rather than a local) mechanism(s) already occurring in relatively early stages (Global Initiative for Chronic Obstructive Lung Disease stage II) of the disease.

KEYWORDS: Chronic obstructive pulmonary disease pathophysiology, muscle disorders, oxidative stress, quadriceps muscle, reactive oxygen species, respiratory muscles

hronic obstructive pulmonary disease (COPD) is frequently associated with several extra-pulmonary manifestations that significantly influence the course and prognosis of the disease [1]. Skeletal muscle dysfunction (SMD), one of the first systemic effects of COPD identified, contributes to limit exercise capacity and to jeopardise health status in these patients [2]. Furthermore, it heralds poor prognosis, independently of the degree of airflow limitation [3]. Thus, a better understanding of the mechanisms leading to SMD in COPD is of great clinical interest.
Previous studies have described a number of cellular and molecular abnormalities in the skeletal muscle of patients with COPD that can contribute to SMD. These include, among others, a shift in the fibre type distribution, the presence of fibre atrophy, evidence of oxidative and nitrosative stress, protein nitrosylation and enhanced apoptosis [2, 4-6]. Despite the fact that mitochondria are involved in energy production and oxidative metabolism, as well as in the control of apoptosis, direct measurements of mitochondrial function in COPD muscles have seldom been obtained. SAULEDA et al. [7] were the

Earn CME accreditation by answering questions about this article. You will find these at the back of the printed copy of this issue or online at www.erj.ersjournals.com/current.dtl

AFFILIATIONS

*Servicio de Neumología,

\#Unidad de Medicina y Cirugía

Experimental, and

"Servicio de Cirugía de Tórax, Hospital General Universitario

Gregorio Marañón, Madrid

+Servicio de Cirugía de Tórax and

${ }^{\S}$ Servicio de Neumología, Fundación Jiménez Díaz, Madrid,

${ }^{f}$ CIBER Enfermedades Respiratorias

(CIBERES), Instituto de Salud Carlos III, Madrid,

**Servicio Neumología, Hospital

Universitario Son Dureta, Palma, and

\#\#Fundación Caubet-Cimera,

Bunyola, Mallorca, Spain.

CORRESPONDENCE

L. Puente-Maestu,

Servicio de Neumología

Hospital General Universitario

Gregorio Marañón

c/ Doctor Ezquerdo 46

28007 Madrid, Spain

Fax: 34915868018

E-mail: Ipuente@separ.es and

Ipuente.hgugm@salud.madrid.org

Received:

July 222008

Accepted after revision:

December 052008

SUPPORT STATEMENT

CIBERES is an initiative of the

Instituto de Salud Carlos III

(Ministerio de Ciencia e Innovación, Madrid, Spain). The present study

was supported by the Fondo de

Investigaciones Sanitarias

(PI052563) and Neumomadrid (both in Madrid).

STATEMENT OF INTEREST

None declared.

European Respiratory Journal

Print ISSN 0903-1936

Online ISSN 1399-3003 
first to report that the activity of cytochrome oxidase (COX), the terminal enzyme of the mitochondrial electron transport chain, was upregulated in skeletal muscle of COPD patients in direct proportion to arterial hypoxaemia. More recently, GOSKER et al. [8] found that the content of uncoupling protein 3 (a protein channel that facilitates proton leak, thus uncoupling oxidative phosphorylation from ATP synthesis, with energy dissipated as heat) was decreased in skeletal muscle of patients with COPD. Finally RIBERA et al. [9] reported increased mitochondrial electron transport in saponineskinned isolated fibres of respiratory muscles of severe emphysematous patients. Collectively, these observations suggest that mitochondrial function in skeletal muscle of COPD patients may be altered.

The present study sought to extend these previous and partial observations by comprehensively characterising mitochondrial function in skeletal muscles of patients with COPD. To this end, state 3 and 4 respiration, ATP production, the activities of COX, respiratory chain complex I+III and citrate synthase (CS) and the production of reactive oxygen species (ROS) were determined in mitochondria isolated from the vastus lateralis (VL) of patients with moderate COPD and control subjects with normal lung function, matched for age and degree of regular physical activity. Furthermore, because respiratory muscles seem to behave differently from skeletal muscle in patients with COPD [7], mitochondria isolated from the external intercostalis (EI) were also studied in these same patients.

\section{METHODS}

\section{Study design}

Biopsies from VL and EI were obtained during thoracic surgery for lung cancer (stage I or II) in 13 patients with moderate COPD [1] and 19 patients with normal lung function and no significant comorbidities or locomotor dysfunction. None of them had received chemotherapy before biopsies were obtained. All participants signed an informed consent after being fully aware of the objectives and nature of the study. The Institutional Committee for Ethics in Human Research of the Hospital General Universitario Gregorio Marañón (Madrid, Spain) had approved the study. All the aspects of the present study comply with the declaration of Helsinki.

\section{Lung function and physical activity}

Spirometry was performed using a Neumoscreen II (Jaeger, Hochberg, Germany) spirometer following international guidelines [10]. Regular physical activity was evaluated by the International Physical Activity Questionnaire [11]. To further characterise the exercise capacity of participants, all of them performed an incremental exercise test on an electromagnetically braked cycle-ergometer (ER-900; Jaeger) using a ramp protocol at $20 \mathrm{~W} \cdot \mathrm{min}^{-1}$ to a symptom-limited maximum. Ventilation and pulmonary gas exchange were measured breath-by-breath by a Quark $b^{2}$ cardiopulmonary exercise system (Cosmed, Rome, Italy).

\section{Investigations on isolated mitochondria}

Surgical biopsies of VL and EI were obtained while the patient was anaesthetised, by performing a small incision about $25 \mathrm{~cm}$ proximal to the patella (VL) and from the incised muscles during thorax opening at the level of the 5th or 6th intercostal spaces (EI). Biopsies were transferred within $1 \mathrm{~min}$ to ice-cold isolation buffer (300 mM manitol, $1 \mathrm{mM}$ EGTA, $10 \mathrm{mM}$ Trizma-HCl (Sigma-Aldrich Co., St Louis, MO, USA), $1 \mathrm{mM}$ $\mathrm{KH}_{2} \mathrm{PO}_{4}, 1.74 \mathrm{mg} \cdot \mathrm{mL}^{-1}$ phenylmethyl sulphonyl fluoride, $0.2 \%$ bovine serum albumin, $10 \mathrm{mg} \cdot \mathrm{L}^{-1}$ amoxicillin, $\mathrm{pH}$ 7.4). The muscle samples were then placed on a Petri plaque surrounded by ice slurry. Mitochondria were isolated from these biopsies following previously described methodology [12]. Briefly, after dissecting the fat and fibrous tissue, samples were weighed, washed with EGTA and chopped up into small pieces with a blade and suspended in isolation buffer (1:2 wt:vol). This was then homogenised with a Potter-Eveljehm homogeniser (B. Braun Medical AG, Emmenbrücke, Germany) avoiding heating of the sample. The homogenate was centrifuged at $4^{\circ} \mathrm{C}$ in a Sorvall RC-5, rotor SS-34, once for $10 \mathrm{~min}$ at $1,075 \times g$, followed by three steps of $10 \mathrm{~min}$ at $8,635 \times g$ at $4^{\circ} \mathrm{C}$. The final mitochondrial pellet was resuspended in an Eppendorf tube with $150 \mu \mathrm{L}$ of measurement buffer (300 mM Manitol, $10 \mathrm{mM}$ Trizma- $\mathrm{HCl}, 1 \mathrm{mM} \mathrm{KH_{2 }} \mathrm{PO}_{4}$, $\mathrm{pH}$ 7.4) and stored on ice.

Mitochondrial oxygen consumption $\left(V^{\prime} \mathrm{O}_{2}, \mathrm{~m}\right)$ was measured with a Clark-type electrode (YSI Inc., Yellow Springs, $\mathrm{OH}$, USA) in a metacrilate chamber at $37^{\circ} \mathrm{C}$ equipped with magnetic stirring in the presence of $10 \mu \mathrm{L}$ of succinate $5 \mathrm{mM}$ with (state 3) or without (state 4) ADP $5 \mathrm{mM} . V^{\prime} \mathrm{O}_{2}, \mathrm{~m}$ was expressed in $\mathrm{mmol} \cdot \mathrm{min}^{-1} \cdot \mathrm{kg}^{-1}$ of muscle tissue. The respiratory control index (RCI) was calculated as the ratio of state 3 to state 4 rates of respiration. ATP synthesis was indirectly assessed by measuring spectrophotometrically (Uvikon 930 spectrofluorometer; Kontron, Milan, Italy) the increase in reduced nicotinamide adenine dinucleotide phosphate (NADPH) concentration coupled to glucose phosphorylation by hexoquinase and later oxidation of glucose-6-phosphate to 6-phosphogluconate by glucose-6-phosphate dehydrogenase [13]. To account for potential differences in mitochondrial density, measured values of state 3 and $4 V^{\prime} \mathrm{O}_{2}, \mathrm{~m}$ and rate of ATP synthesis were expressed as tissue activities [14] in $\mathrm{mmol} \cdot \mathrm{min}^{-1} \cdot \mathrm{kg}^{-1}$ of muscle, i.e. taking into account the dilution factor, the yield of mitochondria (an indirect validated marker of mitochondrial volume density in skeletal muscle) and the biopsy mass. The activities of COX (EC 1.9.3.1, complex IV), CS (EC 2.3.3.1) and complex I+III (rotenone-sensitive NADH cytochrome-c reductase; EC 1.6.2.1) were determined according to previously described spectrophotometric methods [12, 15]. Aliquots of the homogenate and final mitochondrial suspension were assayed for total protein content [16]. Mitochondrial yield was estimated as CS in the mitochondrial suspension relative to that of the actual biopsy. All reagents were obtained from Sigma-Aldrich Co.

ROS production and superoxide dismutase (SOD; EC 1.15.1.1) activity were measured in nine patients with COPD and 10 control subjects. Fixed volumes $(10 \mu \mathrm{L})$ of resuspended mitochondria were incubated with $50 \mu \mathrm{M}$ 5-(and-6)chloromethyl-2' $7^{\prime}$-dichlorodihydrofluorescein diacetate acetyl ester $\left(\mathrm{CM}-\mathrm{H}_{2} \mathrm{DCFDA}\right)$ at $37^{\circ} \mathrm{C}$ for $60 \mathrm{~min}$. ROS production is directly proportional to fluorescence emission (between 480 and $520 \mathrm{~nm}$ ) measured using a multidetection microplate reader (SBL/AMINCO, Rochester, NY, USA). To assess ROS production during states 3 and 4 respiration, $70 \mathrm{mM}$ of ADP and $10 \mathrm{mM}$ of glutamate were added immediately before the 


\begin{tabular}{|c|c|c|c|}
\hline \multirow[t]{2}{*}{ TABLE 1} & \multirow[b]{2}{*}{ Control } & \multirow[b]{2}{*}{ COPD } & \multirow[b]{2}{*}{$p$-value } \\
\hline & & & \\
\hline Age yrs & $67 \pm 9$ & $68 \pm 6$ & NS \\
\hline Weight kg & $72 \pm 9$ & $71 \pm 12$ & NS \\
\hline $\mathrm{BMI} \mathbf{k g} \cdot \mathrm{m}^{-2}$ & $25 \pm 3$ & $26 \pm 4$ & NS \\
\hline $\begin{array}{l}\text { Smoking exposure } \\
\text { pack-yrs }\end{array}$ & $52.1 \pm 9.3$ & $53.0 \pm 5.8$ & NS \\
\hline $\begin{array}{l}\text { Declared current } \\
\text { smokers } \%\end{array}$ & 12.5 & 15.3 & NS \\
\hline Physical activity ${ }^{\#}$ & $1.1 \pm 0.2$ & $1.3 \pm 0.3$ & NS \\
\hline FEV 1 \% pred & $95 \pm 18$ & $66 \pm 15$ & $<0.001$ \\
\hline FEV $1 /$ FVC $\%$ & $77 \pm 6$ & $57 \pm 9$ & $<0.001$ \\
\hline$V^{\prime} \mathrm{O}_{2}$, peak $\%$ pred & $82 \pm 11$ & $73 \pm 11$ & 0.053 \\
\hline$V^{\prime} E / M V V \%$ & $65 \pm 15$ & $81 \pm 8$ & 0.02 \\
\hline Dyspnoea Borg scale & $6.4 \pm 1.4$ & $5.9 \pm 1.4$ & NS \\
\hline Leg fatigue Borg scale & $5.0 \pm 1.2$ & $6.0 \pm 0.7$ & 0.068 \\
\hline Resting $\mathrm{Pa}, \mathrm{O}_{2} \mathrm{mmHg}$ & $75.5 \pm 6.2$ & $66.6 \pm 4.1$ & $<0.001$ \\
\hline Exercise $\mathrm{Pa}_{\mathrm{a}} \mathrm{O}_{2} \mathrm{mmHg}$ & $77.5 \pm 5.1$ & $63.2 \pm 4.1$ & $<0.001$ \\
\hline $\mathrm{COH}^{\star} \%$ & $2.7 \pm 1.4$ & $3.2 \pm 1.51$ & NS \\
\hline \multicolumn{4}{|c|}{$\begin{array}{l}\text { Data are presented as mean } \pm \mathrm{SD} \text {, unless otherwise stated. COPD: chronic } \\
\text { obstructive pulmonary disease; } \mathrm{BMI} \text { : body mass index; FEV1: forced expiratory } \\
\text { volume in one second; \% pred: percentage of predicted value; FVC: forced vital } \\
\text { capacity; } \mathrm{V}^{\prime} \mathrm{O}_{2} \text {,peak: peak oxygen uptake; } V^{\prime} \mathrm{E} / \mathrm{MVV} \text { : ventilatory reserve usage; } \\
\mathrm{Pa}_{1} \mathrm{O}_{2} \text { : arterial oxygen tension; } \mathrm{COHb} \text { : carboxyhaemoglobin; NS: nonsignificant. } \\
\#_{\text {: }} \text { measured by the International Physical Activity Questionnaire; } \\
\text { on the day of the exercise test. } 1 \mathrm{mmHg}=0.133 \mathrm{kPa} \text {. }\end{array}$} \\
\hline
\end{tabular}

addition of $\mathrm{CM}-\mathrm{H}_{2}$ DCFDA. The activity of the SOD was measured by the blue tetrazolium reduction method (SigmaAldrich Co.) [17].

\section{Statistical analysis}

Results are shown as mean $\pm \mathrm{SD}$, unless otherwise specified. Comparisons between groups were performed by paired t-tests. Correlations between variables of interest were explored with the Pearson correlation test. A p-value $<0.05$ was considered significant.

\section{RESULTS \\ Clinical data}

Patients and control subjects were well matched in terms of age, weight, body mass index (BMI) and level of usual physical activity, which was relatively low in both groups (table 1). Patients with COPD had moderate airflow obstruction, whereas spirometry was normal in control subjects (table 1). Exercise tolerance was preserved in both groups, albeit a tendency to lower peak oxygen uptake $\left(V^{\prime} \mathrm{O}_{2}\right.$,peak) was seen in the COPD group. At peak exercise, patients with COPD had less ventilatory reserve $(p=0.02)$. While dyspnoea scores were not different between groups, leg fatigue scores tended to be higher in COPD patients (table 1). Specifically questioned, all the patients declared having stopped smoking at the time of admission to the hospital.

\section{Mitochondrial function}

Table 2 shows mitochondrial function measurements in VL and EI in the two groups of subjects studied. Biopsy weight, mitochondrial yield and mitochondrial protein content were similar in both groups and both muscles, supporting the reproducibility of the methodology used. Compared with control subjects, patients with COPD showed slightly but significantly reduced $V^{\prime} \mathrm{O}_{2}, \mathrm{~m}$ (state 3 ) values and ATP production, both in VL and EI (table 2). The RCI was significantly reduced in the VL of patients with COPD, whereas in the EI, differences just failed to reach statistical significance (table 2). The P:O ratio (i.e. the efficiency of ATP synthesis coupled with cell respiration) was similar $(\sim 1.5)$ in both groups and both

TABLE 2 Mitochondrial function measurements in vastus lateralis and external intercostalis muscles

\begin{tabular}{|c|c|c|c|c|c|c|}
\hline & \multicolumn{3}{|c|}{ Vastus lateralis } & \multicolumn{3}{|c|}{ External intercostalis } \\
\hline & Control & COPD & $p$-value & Control & COPD & p-value \\
\hline Biopsy weight g & $2.2 \pm 1.1$ & $1.8 \pm 0.6$ & NS & $1.4 \pm 0.5$ & $1.4 \pm 0.6$ & NS \\
\hline Mitochondrial yield \% & $35.6 \pm 4.2$ & $34.2 \pm 3.1$ & NS & $34.1 \pm 5.1$ & $34.7 \pm 4.5$ & NS \\
\hline Mitochondrial protein $\mathbf{g} \cdot \mathbf{k g}^{-1}$ & $9.5 \pm 1.4$ & $9.4 \pm 2.7$ & NS & $9.4 \pm 2.5$ & $8.9 \pm 2.7$ & NS \\
\hline $\mathrm{V}^{\prime} \mathrm{O}_{2}, \mathrm{~m}$ state $3^{-} \mathrm{mmol} \cdot \mathrm{min}^{-1} \cdot \mathrm{kg}^{-1}$ & $3.6 \pm 0.4$ & $2.9 \pm 0.3$ & 0.002 & $4.1 \pm 0.4$ & $3.6 \pm 0.3$ & 0.03 \\
\hline $\mathrm{V}^{\prime} \mathrm{O}_{2}, \mathrm{~m}$ state $4^{-} \mathrm{mmol} \cdot \mathrm{min}^{-1} \cdot \mathrm{kg}^{-1}$ & $0.71 \pm 0.21$ & $0.80 \pm 0.16$ & NS & $0.71 \pm 0.48$ & $0.73 \pm 0.32$ & NS \\
\hline $\operatorname{cox} \mu \mathrm{mol} \cdot \mathrm{min}^{-1} \cdot \mathrm{mg}^{-1}$ & $2.0 \pm 0.8$ & $3.0 \pm 0.7$ & 0.0001 & $2.4 \pm 0.9$ & $3.7 \pm 1.6$ & 0.02 \\
\hline Complex I-III $\mu \mathrm{mol} \cdot \mathrm{min}^{-1} \cdot \mathrm{mg}^{-1}$ & $1.8 \pm 0.9$ & $2.3 \pm 0.7$ & NS & $2.1 \pm 0.9$ & $2.8 \pm 1.0$ & 0.04 \\
\hline $\mathrm{CS} \mu \mathrm{mol} \cdot \mathrm{min}^{-1} \cdot \mathrm{mg}^{-1}$ & $18.5 \pm 2.7$ & $16.4 \pm 2.2$ & 0.03 & $20.5 \pm 2.8$ & $19.5 \pm 3.1$ & NS \\
\hline ATP production $\mu \mathrm{mol} \cdot \mathrm{min}^{-1} \cdot \mathrm{kg}^{-1}$ & $5.4 \pm 0.9$ & $4.6 \pm 1.1$ & 0.03 & $6.1 \pm 0.8$ & $5.4 \pm 0.9$ & 0.05 \\
\hline
\end{tabular}

Data are presented as mean $\pm S D$, unless otherwise stated. COPD: chronic obstructive pulmonary disease; $\mathrm{RCl}$ : respiratory control index; $V^{\prime} \mathrm{O}_{2}, \mathrm{~m}$ : mitochondrial oxygen consumption, measured in the presence of succinate with (state 3) or without (state 4) a saturating concentration of ADP; COX: cytochrome oxidase; CS: citrate synthase; NS: nonsignificant. ${ }^{\#}$ : rate of ATP synthesis per rate of respiration; " the yield of mitochondria and the biopsy mass. 
muscles (table 2). Compared with control subjects, the activity of CS (a mitochondrial matrix enzyme) was also reduced in the VL of subjects with COPD (table 2). In contrast, the activity of mitochondrial membrane enzymes (COX and complex I-III) was significantly higher in COPD patients than in control subjects in both muscles (table 2). There were modest but significant $(\mathrm{p}<0.01)$ correlations between the $V^{\prime} \mathrm{O}_{2}$, peak of the incremental exercise test and CS $(\mathrm{r}=0.58)$ and state 3 respiration $(\mathrm{r}=0.65)$. Interestingly, COX activity was negatively related to arterial oxygen tension $\left(\mathrm{Pa}_{\mathrm{a}} \mathrm{O}_{2}\right)$, at rest and during exercise (fig. 1). A similar relationship was observed with the activities of the other respiratory chain enzymes (data not shown).

\section{ROS production and SOD activity}

During state 3 respiration (ADP-stimulated; fig. 2a) the production of ROS was significantly higher $(p<0.01)$ in patients with COPD than in control subjects, both in VL (2.4-fold increase) and EI (1.7-fold increase). Similar results were observed during state 4 (glutamate-stimulated) respiration (VL 2.9-fold increase, EI 1.8-fold increase; $\mathrm{p}<0.05$; fig. 2b). Figure 2 also corroborates the expectation that ROS production is highest in the absence of ADP (state 4 respiration), when the mitochondrial membrane potential is highest [18]. ROS production was significantly $(\mathrm{p}<0.001)$ related to complex I+III activity in both state 4 and state 3, as shown in figure 3,
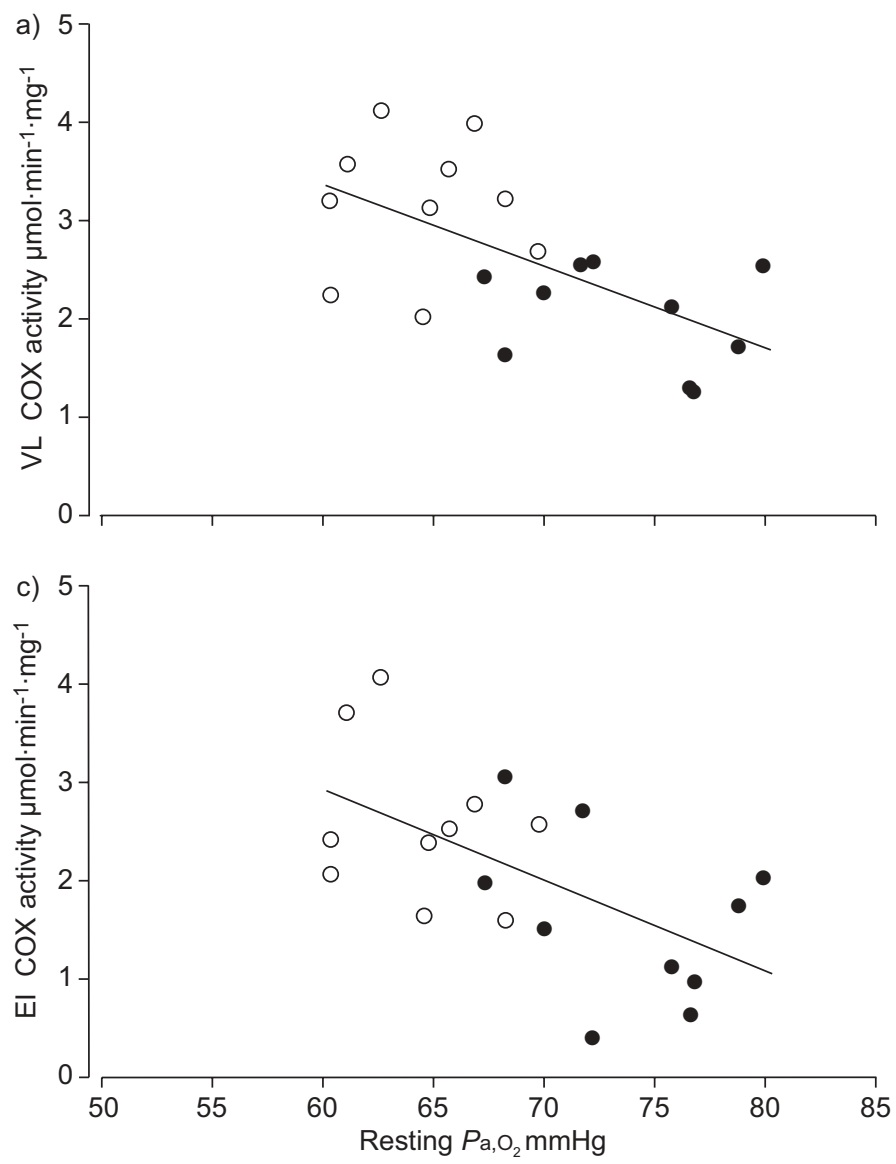

indicating, as anticipated, that the mitochondrial electron transport chain is a major source of ROS production in skeletal muscle [19].

The activity of the antioxidant enzyme SOD was increased in mitochondria isolated from the VL in patients with COPD $(p<0.05)$, but differences failed to reach statistical significance in EI samples (fig. 2c).

\section{DISCUSSION}

The present study shows that the mitochondria isolated from the VL and EI of COPD patients present increased ROS production and a set of abnormalities consistent with mitochondrial membrane blockade [20,21] (table 2 and figs 1 and 2).

\section{Previous studies}

Several studies have previously investigated aspects of mitochondrial function in muscle biopsies of patients with COPD. To the current authors' knowledge, the present study is the first describing mitochondrial function comprehensively in both peripheral and respiratory muscles in these patients. SAULEDA et al. [7] reported increased COX activity in the VL of patients with COPD. The current results are in keeping with this observation (table 2 and fig. 1) and extend it by showing that the activities of other membrane-bound respiratory chain enzymes are also upregulated in patients with COPD (table 2).

b)

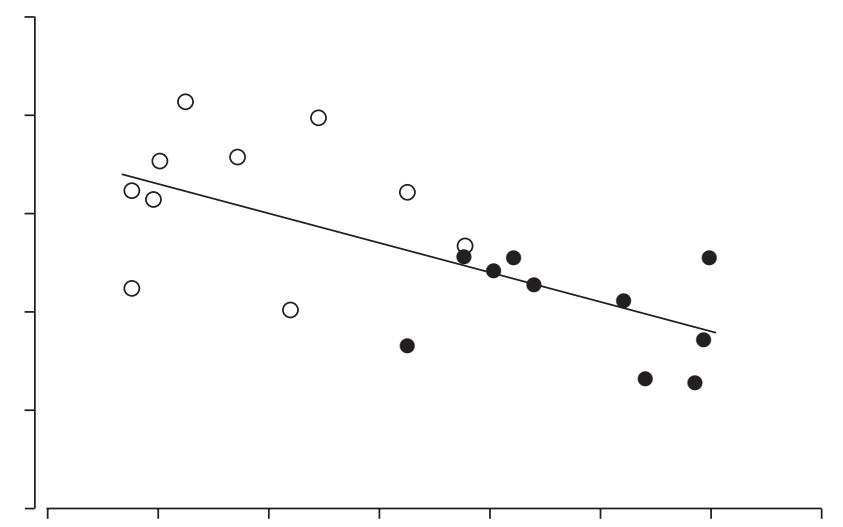

d)

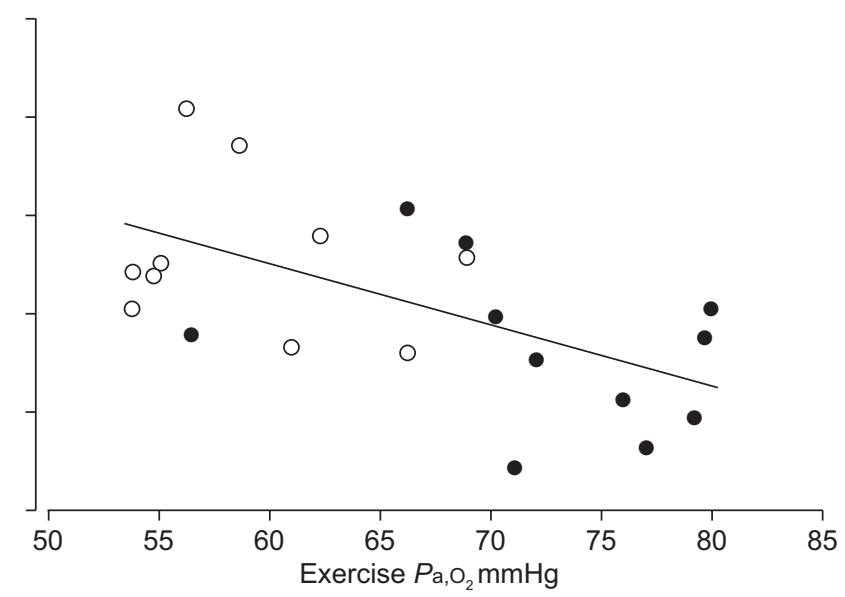

FIGURE 1. Correlation between arterial oxygen tension $\left(\mathrm{Pa}_{\mathrm{a}} \mathrm{O}_{2}\right)$ and cytochrome oxidase (COX) activity in a and $\left.\mathrm{b}\right)$ vastus lateralis $(\mathrm{VL}) \mathrm{and} \mathrm{c}$ and $\left.\mathrm{d}\right) \mathrm{external}$ intercostalis (El) muscles; $a$ and c) at rest and $b$ and d) during exercise. - : control subjects; $O$ : chronic obstructive pulmonary disease patients. a) $r=-0.60, p<0.01 ; b) r=-0.66$, $p<0.01$; $) r=-0.55, p<0.01$; d) $r=-0.59, p<0.01$. 

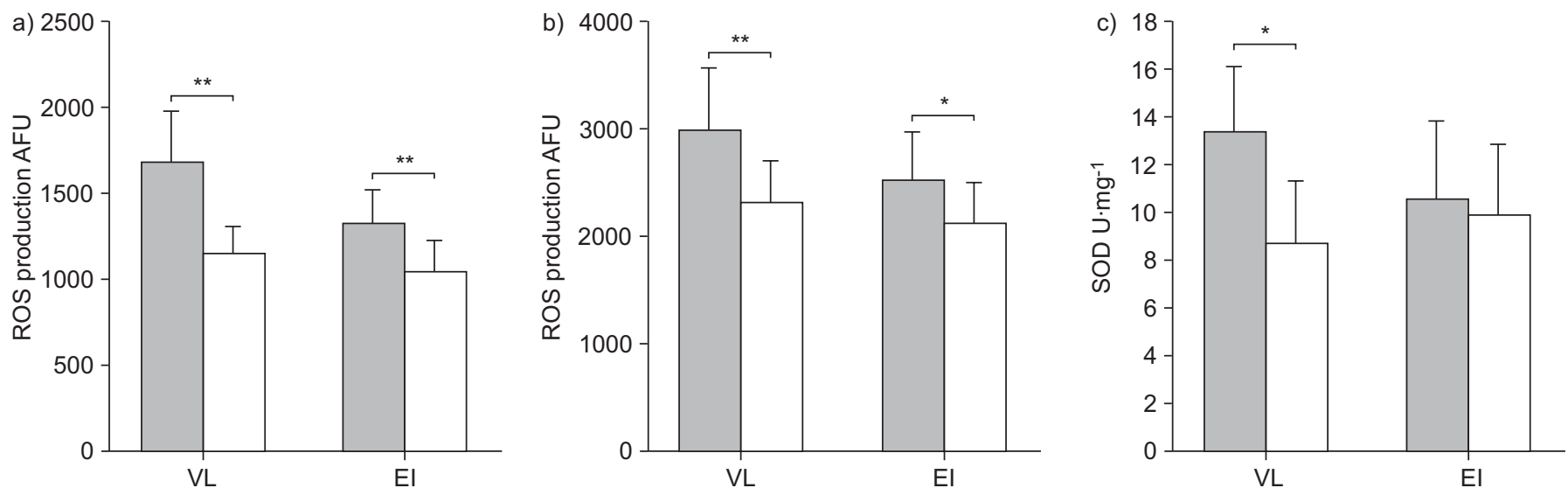

FIGURE 2. Mean \pm SD reactive oxygen species (ROS) production (in arbitrary fluorescence units (AFU)) in isolated mitochondria from the vastus lateralis (VL) and external intercostalis (EI) muscles of chronic obstructive pulmonary disease patients ( $\square$ ) and control subjects ( $\square$ ) during a) state 3 (ADP-stimulated) and b) state 4 (glutamate-stimulated) respiration. c) Mean $\pm \mathrm{SD} \mathrm{Mn}^{2+}$ superoxide dismutase (SOD) activity. ${ }^{*}: \mathrm{p}<0.05$; ${ }^{* *}$ : $\mathrm{p}<0.01$.

Also in keeping with some former studies [22-24], the present study found decreased CS activity in the VL (table 2). CS is a citric acid cycle enzyme of the mitochondrial matrix. Thus, the heterogeneous alteration of the mitochondrial oxidative metabolism enzymes found in patients with COPD suggests that the activities of the citric acid cycle and the electron transport chain are unmatched in these patients [14,25] and points to different regulatory mechanism for both types of
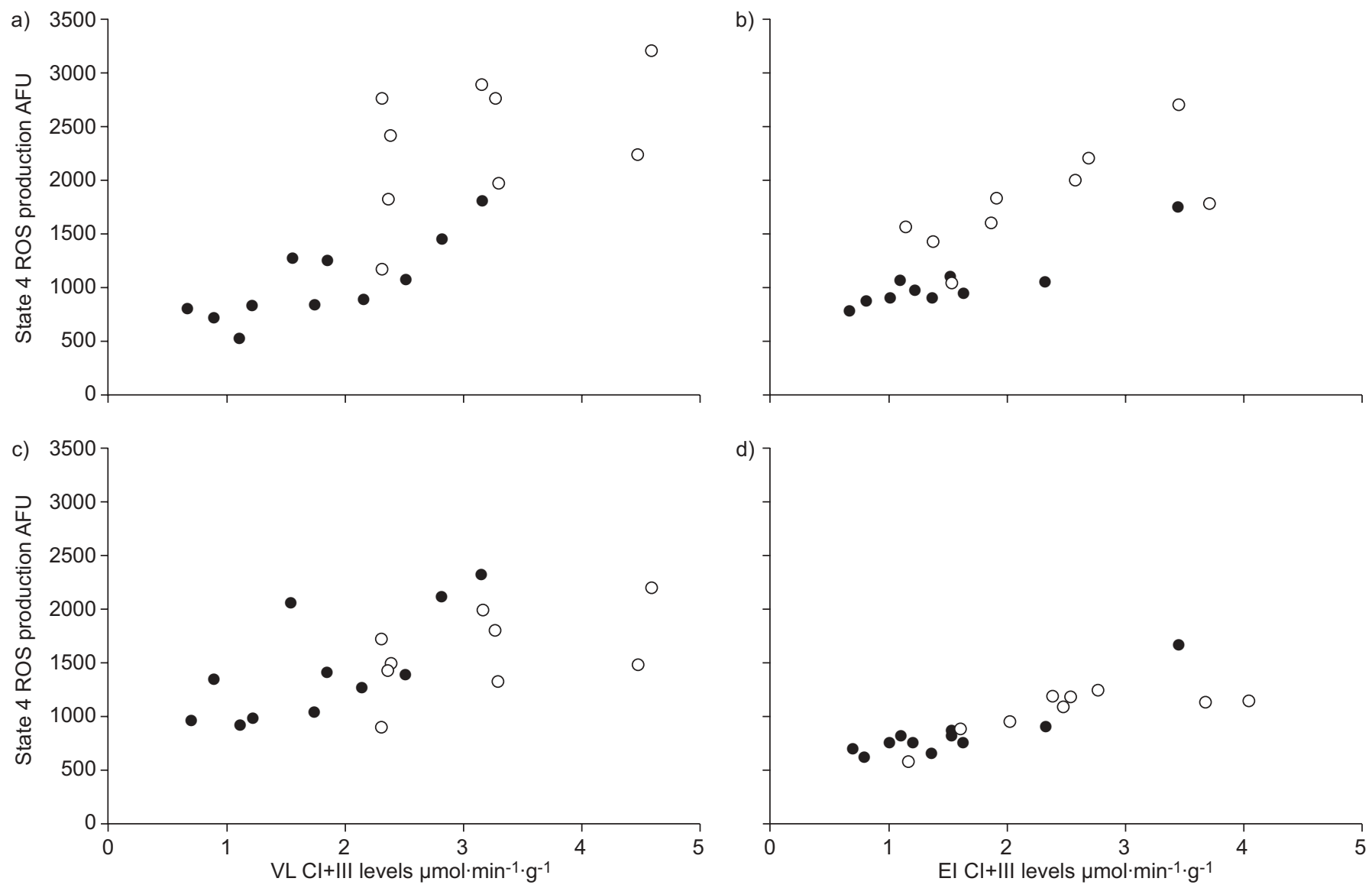

FIGURE 3. Relationship between complex (C) I+III (rotenone-sensitive reduced nicotinamide adenine dinucleotide cytochrome-c reductase) activity and reactive oxygen species (ROS) production during a and b) state 4 and $\mathrm{c}$ and d) state 3 respiration, in a and c) vastus lateralis (VL) and b and d) external intercostalis (El) muscles. AFU: arbitrary fluorescents units. - control subjects; $O$ : chronic obstructive pulmonary disease patients. a) $r=0.74 ; b) ~ r=0.78 ; c) ~ r=0.81 ; d) ~ r=0.84$. 
mitochondrial enzymes. In fact, COX and complex III are partially coded by mitochondrial DNA, while citric acid enzymes are regulated by nucleic DNA [26].

Increased ROS production by COPD striated muscle has been previously suspected from indirect findings [27]; however, the present study actually measured it (figs 2 and 3). Superoxide anions are produced by the electron transport chain on the inner mitochondrial membrane [19] and their generation is strongly dependent upon the proton potential across the mitochondrial membrane [18]. This potential was probably increased in the COPD mitochondria as a consequence of the increased respiratory enzyme activity together with the mitochondrial respiratory membrane blockade suggested by the lack of translation into more oxygen uptake [20, 21]. Finally, RABINOVICH et al. [28] reported reduced RCI in patients with COPD and low BMI. The present results extend these findings to the VL of subjects with normal BMI (table 1).

\section{Mechanisms}

The present study is a descriptive study that does not address potential mechanisms directly. However, the observations allow some speculation. That mitochondrial dysfunction occurred in COPD both in skeletal and respiratory muscles (table 2) suggests a systemic, rather than a local factor(s). Sedentarism, a frequently quoted mechanism in these patients, can be excluded, because both groups had similar activity history and both had a reasonably preserved exercise capacity (table 1). Smoking may have influenced mitochondrial function [21]; however, as shown in table 1, there were no apparent differences in cumulative smoking exposure, carboxyhaemoglobin levels and/or percentage of current smokers between the groups. SAULEDA et al. [7] reported increased COX activity in the VL of patients with COPD in proportion to arterial hypoxaemia. The current results also found an inverse relationship between respiratory chain activity and $\mathrm{Pa}_{1} \mathrm{O}_{2}$ (fig. 1). This suggests that tissue hypoxia may upregulate respiratory chain enzymes, thus contributing to mitochondrial dysfunction. The absence of resting arterial hypoxaemia does not exclude this possibility because it may occur during exercise (fig. 1) or sleep. An abnormal microcirculatory control that may eventually result in tissue hypoxia can not be excluded either [29]. Finally, low-grade chronic systemic inflammation in COPD [30] may be another potential mechanism because inflammatory cytokines are related to basal energy metabolism and are known to trigger the production of ROS by striated muscle fibres [27].

\section{Implications}

Mitochondrial capacity is a well known limiting factor for exercise performance [14]. The current observations of a correlation between state 3 respiration, CS activity and exercise capacity suggests that the functional abnormalities identified can contribute to limit exercise in patients with COPD. Conversely, it is worth noting that the enhanced ROS production observed in patients with COPD (fig. 2) can produce further skeletal muscle damage through several non-mutually exclusive pathways. First, oxidative stress can alter the structure of several components of the respiratory chain [31] and cause proton leak and mitochondrial uncoupling [20, 32], particularly during exercise [14, 33]. As a consequence, the potential for physical activity in these patients and/or their resistance to fatigue under conditions of increased respiratory load, such as episodes of exacerbation of COPD, may be impaired. Secondly, oxidative stress can be involved in muscle atrophy, a well recognised poor prognostic factor in COPD [3], since it alters the structure of muscle proteins, including myosin, facilitating their degradation by the ubiquitin-proteosome system [6, 34]. It can also trigger apoptosis, an event described in the skeletal muscle of COPD patients [35]. Finally, excessive ROS production deteriorates mitochondrial DNA and contributes to perpetuating muscle damage [36].

\section{Potential limitations}

Several potential limitations of the current study deserve comment. First, mitochondrial function was measured in vitro. Although this was done under strictly controlled experimental conditions following the same standard methodology in both groups [19], the results cannot be readily extrapolated to in vivo conditions. The fact that a high yield $(\sim 35 \%)$ of functionally intact mitochondria [12] was obtained and values of RCI, P:O ratio and $V^{\prime} \mathrm{O}_{2}$, m (table 2) were similar to previously published results [33, 37, 38] indicates good preservation of the organelle's membrane and supports the adequacy of the current study methodology. Moreover, previous studies using similar isolation procedures showed a good relationship between mitochondrial respiration in vitro and muscle maximum oxygen consumption in vivo [14]. Secondly, using succinate, as in the present study, will provide electron input starting from complex II that typically renders lower state 3 $V^{\prime} \mathrm{O}_{2}, \mathrm{~m}$ (about $85 \%$ of the maximal state 3 respiration measured with other substrates) [33, 38]. However, this fact will not substantially alter the current conclusions, since COPD results were compared with non-COPD control subjects studied in exactly the same way. Thirdly, smoking may have influenced the current results, but declared smoking history and carboxyhaemoglobin levels were similar between patients and control subjects. Furthermore, because smoking is forbidden in the hospital, it is likely that the majority (if not all) current smokers had not smoked during the $24 \mathrm{~h}$ they were hospitalised before surgery, when muscle samples were obtained. Fourthly, the subjects studied had localised lung cancer. The present approach has been used in other studies of respiratory muscles in COPD [9] and the current authors do not believe that it influenced the results because the same happened in both patients and control subjects and previous work has found no differences in the structural characteristics and expression of inflammatory cytokines and growth factors in samples from EI of patients with localised lung cancer [39]. Finally, patients with mild-to-moderate COPD and normal BMI (table 1) were studied, so results may be different in more advanced stages of the disease.

\section{Conclusions}

Patients with mild-to-moderate chronic obstructive pulmonary disease show evidence of mitochondrial blockade in both skeletal and respiratory muscles, suggesting that functional mitochondrial abnormalities occur in relation to systemic (as opposed to local) factors, and that they are already present at moderate stages of the disease (Global Initiative for Chronic Obstructive Lung Disease stage II). 


\section{ACKNOWLEDGEMENTS}

The authors thank the patients participating in this study for their willingness to contribute to the advancement of science. They are also grateful to A.L. Andreu and H. García-Arumí (Centre d'Investigació en Bioquímica i Biologia Molecular, University Hospital Vall d'Hebron, Barcelona, Spain) for their help in the determination of the complex I-III of the respiratory chain.

\section{REFERENCES}

1 Rabe KF, Hurd S, Anzueto A, et al. Global strategy for the diagnosis, management, and prevention of chronic obstructive pulmonary disease: GOLD executive summary. Am J Respir Crit Care Med 2007; 176: 532-555.

2 Skeletal muscle dysfunction in chronic obstructive pulmonary disease. A statement of the American Thoracic Society and European Respiratory Society. Am J Respir Crit Care Med 1999; 159: S1-S40.

3 Schols AM, Slangen J, Volovics L, Wouters EF. Weight loss is a reversible factor in the prognosis of chronic obstructive pulmonary disease. Am J Respir Crit Care Med 1998; 157: 1791-1797.

4 Wüst RC, Degens H. Factors contributing to muscle wasting and dysfunction in COPD patients. Int J Chron Obstruct Pulmon Dis 2007; 2: 289-300.

5 Wouters EF. Chronic obstructive pulmonary disease. 5: systemic effects of COPD. Thorax 2002; 57: 1067-1070.

6 Ottenheijm CA, Heunks LM, Dekhuijzen PN. Diaphragm muscle fiber dysfunction in chronic obstructive pulmonary disease: toward a pathophysiological concept. Am J Respir Crit Care Med 2007; 175: 1233-1240.

7 Sauleda J, García-Palmer F, Wiesner RJ, et al. Cytochrome oxidase activity and mitochondrial gene expression in skeletal muscle of patients with chronic obstructive pulmonary disease. Am J Respir Crit Care Med 1998; 157: 1413-1417.

8 Gosker HR, Schrauwen P, Hesselink MK, et al. Uncoupling protein-3 content is decreased in peripheral skeletal muscle of patients with COPD. Eur Respir J 2003; 22: 88-93.

9 Ribera F, N'Guessan B, Zoll J, et al. Mitochondrial electron transport chain function is enhanced in inspiratory muscles of patients with chronic obstructive pulmonary disease. Am J Respir Crit Care Med 2003; 167: 873-879.

10 Miller MR, Hankinson J, Brusasco V, et al. Standardisation of spirometry. Eur Respir J 2005; 26: 319-338.

11 Booth M. Assessment of physical activity: an international perspective. Res Q Exerc Sport 2000; 71: Suppl. 2, S114-S120.

12 Rustin $\mathrm{P}$, Chretien D, Bourgeron T, et al. Biochemical and molecular investigations in respiratory chain deficiencies. Clin Chim Acta 1994; 228: 35-51.

13 Trautschold I, Lamprecht W, Schweitzer G. Adenosine 5 'triphosphate. UV method with hexokinase and glucose 6-phosphate dehydrogenase. In: Bergmeyer HU, Bergmeyer J, Grassl M, eds. Methods of Enzymatic Analysis. Weinheim, VCH Verlagsgesellschaft, 1985; pp. 346-357.

14 Rasmussen UF, Rasmussen HN, Krustrup P, Quistorff B, Saltin B, Bangsbo J. Aerobic metabolism of human quadriceps muscle: in vivo data parallel measurements on isolated mitochondria. Am J Physiol Endocrinol Metab 2001; 280: E301-E307.
15 Fischer JC, Ruitenbeek W, Berden JA, et al. Differential investigation of the capacity of succinate oxidation in human skeletal muscle. Clin Chim Acta 1985; 153: 23-36.

16 Bradford MM. A rapid and sensitive method for the quantitation of microgram quantities of protein utilizing the principle of protein-dye binding. Anal Biochem 1976; 72 248-254.

17 van den Berg R, Haenen GRMM, van den Berg H, Bast A. Applicability of an improved Trolox equivalent antioxidant capacity (TEAC) assay for evaluation of antioxidant capacity measurements of mixtures. Food Chem 1999; 66: 511-517.

18 Korshunov SS, Skulachev VP, Starkov AA. High protonic potential actuates a mechanism of production of reactive oxygen species in mitochondria. FEBS Lett 1997; 416: 15-18.

19 Chen Q, Vazquez EJ, Moghaddas S, Hoppel CL, Lesnefsky EJ. Production of reactive oxygen species by mitochondria: central role of complex III. J Biol Chem 2003; 278: 36027-36031.

20 Harper ME, Bevilacqua L, Hagopian K, Weindruch R, Ramsey JJ. Ageing, oxidative stress, and mitochondrial uncoupling. Acta Physiol Scand 2004; 182: 321-331.

21 van der Toorn M, Slebos DJ, de Bruin HG, et al. Cigarette smoke-induced blockade of the mitochondrial respiratory chain switches lung epithelial cell apoptosis into necrosis. Am J Physiol Lung Cell Mol Physiol 2007; 292: L1211-L1218.

22 Jakobsson P, Jorfeldt L, Henriksson J. Metabolic enzyme activity in the quadriceps femoris muscle in patients with severe chronic obstructive pulmonary disease. Am J Respir Crit Care Med 1995; 151: 374-377.

23 Maltais F, Simard AA, Simard C, Jobin J, Desgagnés P, LeBlanc P. Oxidative capacity of the skeletal muscle and lactic acid kinetics during exercise in normal subjects and in patients with COPD. Am J Respir Crit Care Med 1996; 153: 288-293.

24 Puente-Maestu L, Tena T, Trascasa C, et al. Training improves muscle oxidative capacity and oxygenation recovery kinetics in patients with chronic obstructive pulmonary disease. Eur J Appl Physiol 2003; 88: 580-587.

25 Blomstrand E, Rådegran G, Saltin B. Maximum rate of oxygen uptake by human skeletal muscle in relation to maximal activities of enzymes in the Krebs cycle. J Physiol 1997; 501: 455-460.

26 Genome database: map of the human mitochondrial genome (Human Genome Project). http:/ / www.ncbi.nlm. nih.gov/sites/entrez? $\mathrm{db}=$ genome\&cmd $=$ Retrieve\&dopt $=$ Overview\&list_uids $=12188$ Date last updated: March 31, 2008. Date last accessed: November 17, 2008.

27 Koechlin C, Couillard A, Cristol JP, et al. Does systemic inflammation trigger local exercise-induced oxidative stress in COPD? Eur Respir J 2004; 23: 538-544.

28 Rabinovich RA, Bastos R, Ardite E, et al. Mitochondrial dysfunction in COPD patients with low body mass index. Eur Respir J 2007; 29: 643-650.

29 Swisher AK, Alway SE, Yeater R. The effect of exercise on peripheral muscle in emphysema: a preliminary investigation. COPD 2006; 3: 9-15.

30 Agustí AG, Noguera A, Sauleda J, Sala E, Pons J, Busquets $X$. Systemic effects of chronic obstructive pulmonary disease. Eur Respir J 2003; 21: 347-360. 
31 Servais S, Couturier K, Koubi H, et al. Effect of voluntary exercise on $\mathrm{H}_{2} \mathrm{O}_{2}$ release by subsarcolemmal and intermyofibrillar mitochondria. Free Radic Biol Med 2003; 35: 24-32.

32 Boveris A, Costa LE, Cadenas E. The mitochondrial production of oxygen radicals and cellular aging. In: Cadenas E, Packer L, eds. Understanding the Process of Aging. The Roles of Mitochondria, Free Radicals and Antioxidants. New York, Marcel Dekker, CRC Press, 1999; pp. 1-16.

33 Tonkonogi M, Sahlin K. Rate of oxidative phosphorylation in isolated mitochondria from human skeletal muscle: effect of training status. Acta Physiol Scand 1997; 161: 345-353.

34 Gomes-Marcondes MC, Tisdale MJ. Induction of protein catabolism and the ubiquitin-proteasome pathway by mild oxidative stress. Cancer Lett 2002; 180: 69-74.

35 Agustí AG, Sauleda J, Miralles C, et al. Skeletal muscle apoptosis and weight loss in chronic obstructive pulmonary disease. Am J Respir Crit Care Med 2002; 166: 485-489.

36 Fulle S, Protasi F, Di Tano G, et al. The contribution of reactive oxygen species to sarcopenia and muscle ageing. Exp Gerontol 2004; 39: 17-24.

37 Lee CP, Gu Q, Xiong Y, Mitchell RA, Ernster L. P/O ratios reassessed: mitochondrial $\mathrm{P} / \mathrm{O}$ ratios consistently exceed 1.5 with succinate and 2.5 with NAD-linked substrates. FASEB J 1996; 10: 345-350.

38 Rasmussen UF, Rasmussen HN. Human skeletal muscle mitochondrial capacity. Acta Physiol Scand 2000; 168: 473-480.

39 Casadevall C, Coronell C, Minguella J, et al. [Analysis of respiratory muscle structure and tumor necrosis and insulin-like growth factor expression in chronic obstructive pulmonary disease: are samples valid if obtained during thoracotomy performed because of localized pulmonary neoplasia?]. Arch Bronconeumol 2004; 40: 209-217. 